\title{
Occupational exposure to electromagnetic fields and acute leukaemia: analysis of a case-control study
}

\author{
E V Willett, P A McKinney, N T Fear, R A Cartwright, E Roman
}

Occup Environ Med 2003;60:577-583

See end of article for authors' affiliations

.....................

Correspondence to: Dr E Willett, Leukaemia Research Fund

Epidemiology and Genetics Unit, Margaret Smith Building, University of Leeds, Leeds LS2 9JT, UK;

Eleanor.Willet+@egu.leeds. ac.uk

Accepted 21 September 2002

\begin{abstract}
Aims: To investigate whether the risk of acute leukaemia among adults is associated with occupational exposure to electromagnetic fields.

Methods: Probable occupational exposure to electromagnetic fields at higher than typical residential levels was investigated among 764 patients diagnosed with acute leukaemia during 1991-96 and 1510 sex and age matched controls. A job exposure matrix was applied to the self reported employment histories to determine whether or not a subject was exposed to electromagnetic fields. Risks were assessed using conditional logistic regression for a matched analysis.

Results: Study subjects considered probably ever exposed to electromagnetic fields at work were not at increased risk of acute leukaemia compared to those considered never exposed. Generally, no associations were observed on stratification by sex, leukaemia subtype, number of years since exposure stopped, or occupation; there was no evidence of a dose-response effect using increasing number of years exposed. However, relative to women considered never exposed, a significant excess of acute lymphoblastic leukaemia was observed among women probably exposed to electromagnetic fields at work that remained increased irrespective of time prior to diagnosis or job ever held.

Conclusion: This large population based case-control study found little evidence to support an association between occupational exposure to electromagnetic fields and acute leukaemia. While an excess of acute lymphoblastic leukaemia among women was observed, it is unlikely that occupational exposure to electromagnetic fields was responsible, given that increased risks remained during periods when exposure above background levels was improbable.
\end{abstract}

l nterest in electromagnetic fields as a possible cause of leukaemia was first sparked when Wertheimer and Leeper ${ }^{1}$ observed an association between household electromagnetic fields from overhead power lines and childhood leukaemia. During a subsequent investigation of occupational mortality, Milham² similarly reported that adults employed in occupations involving exposure to electric or magnetic fields experienced increased leukaemia mortality. Possible associations between leukaemia and electromagnetic fields have since been continually tested in epidemiological studies, the most comprehensive investigations using job exposure matrices constructed from exposure measurements of the present day workforce, ${ }^{3-20}$ while others have implemented employment in "electrically related" occupations as a proxy for exposure. ${ }^{271-31}$ This paper presents the findings for men's and women's occupational exposure to electromagnetic fields from a large population based case-control study of acute leukaemia using a new definition of work related electromagnetic field exposure.

\section{MATERIALS AND METHODS}

Details of the study are published elsewhere. ${ }^{32}$ Briefly, cases recruited into the study were persons aged 16-69 years who were newly diagnosed with acute leukaemia between 1 April 1991 and 31 December 1996 while resident in the English regional health authorities of the South West, Wessex, and Yorkshire, and the counties of Cumbria and Lancashire. All diagnoses were pathologically confirmed. For each case, two controls individually matched on sex, year of birth ( \pm 2 years), and ethnic group were randomly selected from persons registered with the same general practitioner (GP) as the case. Cases were excluded if they had a diagnosis of myelodysplastic syndrome or chronic myeloid leukaemia in the six months, or a malignancy within two years, prior to diagnosis of acute leukaemia, or if they had lived abroad for six months or more in the year prior to diagnosis. Controls ineligible under these criteria were replaced. Cases and controls were invited, with the treating consultant's or GP's consent respectively, to be interviewed; if the case had died before the interview was arranged, the case's partner or a close relative was approached as a suitable surrogate. All participating subjects were asked to complete a pre-interview form, requesting residential, occupational, and medical histories. Subjects were subsequently interviewed face-to-face by trained personnel using a highly structured questionnaire to collect further details of their residential, occupational, and medical histories as well as smoking habits and familial cancer.

A total of 1184 acute leukaemia patients were registered on the study, of which 1066 cases were considered eligible for interview under the study criteria. Interviews were obtained for $838(79 \%)$ cases; 731 (87\%) being with the case and 107 (13\%) being with a surrogate. Permission to interview was refused by $40(4 \%)$ treating consultants, $18(2 \%)$ patients, and $21(2 \%)$ surrogates. A further 149 (14\%) cases were not interviewed, either because a suitable surrogate could not be found, the patient could not be traced, or the subject was interviewed for another study. A total of 3646 potential controls were registered on the study; 106 were ineligible for interview, the GP refused permission to contact 313, no reply was received from 588, and 127 persons had no reason given for nonparticipation. Of the controls who were contacted successfully, $1658(66 \%)$ agreed to participate and $854(34 \%)$ refused.

Abbreviations: ALL, acute lymphoblastic leukaemia; AML, acute myeloid leukaemia; $\mathrm{Cl}$, confidence interval; GP, general practitioner; $\mathrm{OR}$, odds ratio; SOC, 1990 Standard Occupational Classification 
Table 1 Jobs with Standard Occupational Classification (1990) codes considered exposed to electromagnetic fields above typical residential levels

\begin{tabular}{lc}
\hline Job & Job code \\
\hline Computer systems and data processing managers & 126 \\
Electrical engineers & 212 \\
Electronic engineers & 213 \\
Software engineers & 214 \\
Electrical/electronic technicians & 302 \\
Computer analysts/programmers & 320 \\
Air traffic planners and controllers & 330 \\
Medical radiographers & 342 \\
Medical secretaries & 450 \\
Legal secretaries & 451 \\
Typists and word processor operators & 452 \\
Other secretaries, personal assistants, typists, word & 459 \\
processor operators not elsewhere classified & \\
Telephone operators & 462 \\
Radio and telegraph operators, other office communication & 463 \\
system operators & \\
Computer operators, data processing operators, other & 490 \\
office machine operators & \\
Electricians, electrical maintenance fitters & 521 \\
Electrical engineers (not professional) & 522 \\
Cable jointers, lines repairers & 524 \\
Radio, TV, and video engineers & 525 \\
Computer engineers, installation and maintenance & 526 \\
Other electrical/electronic trades not elsewhere classified & 529 \\
\hline
\end{tabular}

Prior to interview, participants were requested to list all occupations that were held for at least six months from leaving full time education to diagnosis. For every occupation, the job title, employer's name and address, and the dates commenced and stopped were noted. At interview, further job and industry descriptions for every change in career were recorded. Occupations were coded using the 1990 Standard Occupational Classification (SOC) ${ }^{33}$ and industries using the 1980 Standard Industrial Classification. ${ }^{34}$

The exposure matrix was primarily based on the coded job title. An occupational hygienist, an epidemiologist, and a research officer considered the probability of exposure to electromagnetic fields of every occupation in SOC using the coding scheme's job descriptions, epidemiological literature involving occupational exposures, and industrial monitoring data. "Probable" exposure was described as occupational contact to electromagnetic fields at levels above typical residential exposures. Table 1 gives occupations in the probable exposure category. By default, occupations not considered probably exposed to electromagnetic fields were deemed unlikely to be exposed to electromagnetic fields. The Health and Safety Executive, the National Radiological Protection Board, the National Grid, and an occupational physician verified the job exposure matrix, which is also being employed in the analysis of the UK Childhood Cancer Study (UKCCS) ${ }^{35}$ and the Fourth Morbidity Study of General Practice. ${ }^{36}$

The job exposure matrix was applied to the work histories of Caucasians subjects aged 20 or more two years before diagnosis. All jobs held for at least six months from leaving full time education up until two years prior to diagnosis were included. A two year latent interval prior to diagnosis was assumed based on the minimum induction period between initial exposure and the onset of leukaemia observed in cohorts exposed to known leukaemogens. ${ }^{37-40}$ Employment in at least one job where exposure to electromagnetic fields may have occurred was sufficient to classify a subject as being probably ever exposed to electromagnetic fields; otherwise a person was considered never to have been exposed. It must be noted that the time period of employment was not considered when determining exposure status. Time employed within each exposed job was accumulated across the work history to give
Table 2 Distribution of Caucasian interviewed cases and controls by lineage, marital status, age left school, number of years worked* and deprivation $\dagger$

\begin{tabular}{|c|c|c|c|c|}
\hline \multirow[b]{2}{*}{ Variable } & \multicolumn{2}{|c|}{ Cases } & \multicolumn{2}{|c|}{ Controls } \\
\hline & $n$ & (\%) & $n$ & (\%) \\
\hline Total & 764 & $(100)$ & 1510 & $(100)$ \\
\hline \multicolumn{5}{|l|}{ Lineageł } \\
\hline AML & 662 & (87) & - & \\
\hline ALL & 92 & (12) & - & \\
\hline Other & 10 & (1) & - & \\
\hline \multicolumn{5}{|l|}{ Marital status } \\
\hline Single & 98 & (13) & 140 & (9) \\
\hline Married & 548 & (72) & 1153 & (76) \\
\hline Divorced/separated & 64 & (8) & 116 & (8) \\
\hline Widowed & 32 & (4) & 66 & (4) \\
\hline Other & 22 & (3) & 35 & (2) \\
\hline \multicolumn{5}{|l|}{ Age left school } \\
\hline$\leqslant 16$ & 645 & (84) & 1228 & (81) \\
\hline$>16$ & 118 & (15) & 282 & (19) \\
\hline Not known & 1 & (0) & 0 & (0) \\
\hline \multicolumn{5}{|c|}{ Number of years worked* } \\
\hline Never worked & 8 & (1) & 7 & (0) \\
\hline$<10$ & 137 & (18) & 269 & (18) \\
\hline $10-19$ & 154 & (20) & 316 & (21) \\
\hline $20-29$ & 127 & (17) & 287 & (19) \\
\hline $30-39$ & 142 & (19) & 309 & (20) \\
\hline$\geqslant 40$ & 137 & (18) & 249 & $(16)$ \\
\hline Not known & 59 & (8) & 73 & (5) \\
\hline \multicolumn{5}{|l|}{ Deprivationt } \\
\hline 1 (least deprived) & 129 & (17) & 315 & (21) \\
\hline 2 & 137 & (18) & 276 & (18) \\
\hline 3 & 131 & (17) & 269 & (18) \\
\hline 4 & 107 & (14) & 214 & (14) \\
\hline 5 & 101 & (13) & 186 & (12) \\
\hline 6 & 85 & (11) & 151 & (10) \\
\hline 7 (most deprived) & 72 & (9) & 93 & (6) \\
\hline Not known & 2 & (0) & 6 & (0) \\
\hline
\end{tabular}

*Number of years worked collated from occupational histories up to two years prior to diagnosis. Of the eight cases and seven controls who had never worked continuously for at least six months, three cases and four controls were in full time education.

tDeprivation coded using categories of the Townsend scores for England and Wales; cases are more likely to live in deprived areas than their matched controls (Pearson's $\chi^{2}=12.95, \mathrm{p}=0.07$ ).

$\ddagger A M L$, acute myeloid leukaemia; ALL, acute lymphoblastic leukaemia. Other acute leukaemias includes five cases of acute biphenotypic leukaemia, and five cases of unspecified acute leukaemia.

the total number of years exposed and the number of years since exposure ceased prior to the two year lag period.

A deprivation indicator was created using the address at diagnosis. For each address, the postcode was validated against the Post Office Postcode Address File using QuickAddress (v2.0) and matched to a 1991 census small area, or "enumeration district", via the PC2ED program available from the Manchester Computing Service (MIDAS). Townsend scores were computed for each enumeration district in England and Wales using data from the 1991 census. $^{41}$ Categorisation of the resulting continuous variable provided a coding scheme for the enumeration districts of the addresses at diagnoses.

Odds ratios (OR) and 95\% confidence intervals (CI) for matched analyses were calculated using conditional logistic regression. ${ }^{42}$ Where statistically significant risk estimates were observed in a matched analysis based on small numbers, an unmatched analysis utilising all controls, adjusted for age and sex as appropriate, was conducted via unconditional logistic regression. All analyses were performed using STATA. ${ }^{43}$

\section{RESULTS}

The present analysis is restricted to Caucasians aged 20 or more two years prior to diagnosis, totalling 764 cases and their 1510 individually matched controls. Among the cases, 662 
Table 3 Number of cases and controls, adjusted odds ratios, and $95 \%$ confidence intervals by lineage and sex for occupational exposure to electromagnetic fields above typical residential levels up to two years prior to diagnosis

\begin{tabular}{|c|c|c|c|c|c|c|c|c|c|c|c|c|}
\hline \multirow[b]{2}{*}{ Exposure status } & \multicolumn{4}{|c|}{ Acute leukaemia } & \multicolumn{4}{|l|}{ AML } & \multicolumn{4}{|l|}{ ALL } \\
\hline & Case & Control & OR & $95 \% \mathrm{Cl}$ & Case & Control & OR & $95 \% \mathrm{Cl}$ & Case & Control & OR & $95 \% \mathrm{Cl}$ \\
\hline Male and female & $(n=764)$ & $(n=1510)$ & & & $(n=662)$ & $(n=1309)$ & & & $(n=92)$ & $(n=181)$ & & \\
\hline Never & 644 & 1266 & 1 & - & 564 & 1097 & 1 & - & 71 & 154 & 1 & - \\
\hline Probable & 120 & 244 & 0.97 & $(0.76$ to 1.24$)$ & 98 & 212 & 0.91 & (0.69 to 1.18 ) & 21 & 27 & 1.70 & (0.86 to 3.35 ) \\
\hline Current & 34 & 73 & 0.92 & $(0.61$ to 1.41$)$ & 26 & 65 & 0.80 & $(0.50$ to 1.28$)$ & 8 & 8 & 2.10 & (0.74 to 5.99 ) \\
\hline Past & 80 & 168 & 0.93 & $(0.69$ to 1.25$)$ & 66 & 144 & 0.89 & (0.64 to 1.23 ) & 13 & 19 & 1.53 & $(0.69$ to 3.37$)$ \\
\hline Not known & 6 & 3 & & & 6 & 3 & & & 0 & 0 & & \\
\hline Male & $(n=431)$ & $(n=848)$ & & & $(n=372)$ & $(n=732)$ & & & $(n=53)$ & $(n=104)$ & & \\
\hline Never & 388 & 744 & 1 & - & 336 & 644 & 1 & - & 46 & 90 & 1 & - \\
\hline Probable & 43 & 104 & 0.81 & (0.55 to 1.18 ) & 36 & 88 & 0.80 & (0.53 to 1.22 ) & 7 & 14 & 0.89 & (0.34 to 2.34 ) \\
\hline Current & 19 & 39 & 0.96 & $(0.54$ to 1.69 ) & 15 & 35 & 0.86 & $(0.46$ to 1.61$)$ & 4 & 4 & 1.65 & $(0.40$ to 6.90$)$ \\
\hline Past & 21 & 65 & 0.62 & $(0.37$ to 1.03 ) & 18 & 53 & 0.65 & $(0.37$ to 1.13 ) & 3 & 10 & 0.58 & $(0.15$ to 2.15$)$ \\
\hline Not known & 3 & 0 & & & 3 & 0 & & & 0 & 0 & & \\
\hline Female & $(n=333)$ & $(n=662)$ & & & $(n=290)$ & $(n=577)$ & & & $(n=39)$ & $(n=77)$ & & \\
\hline Never & 256 & 522 & 1 & - & 228 & 453 & 1 & - & 25 & 64 & 1 & - \\
\hline Probable & 77 & 140 & 1.11 & $(0.80$ to 1.53$)$ & 62 & 124 & 0.98 & $(0.69$ to 1.40$)$ & 14 & 13 & 3.48 & (1.18 to 10.2$)$ \\
\hline Current & 15 & 34 & 0.89 & $(0.47$ to 1.66$)$ & 11 & 30 & 0.73 & $(0.36$ to 1.48$)$ & 4 & 4 & 2.95 & $(0.57$ to 15.3$)$ \\
\hline Past & 59 & 103 & 1.18 & $(0.82$ to 1.71$)$ & 48 & 91 & 1.06 & $(0.71$ to 1.59$)$ & 10 & 9 & 3.74 & (1.10 to 12.7$)$ \\
\hline Not known & 3 & 3 & & & 3 & 3 & & & 0 & 0 & & \\
\hline
\end{tabular}

Odds ratios, adjusted for deprivation, estimated using conditional logistic regression using never exposed as reference.

Table 4 Number of male cases and controls, adjusted odds ratios and $95 \%$ confidence intervals by lineage for jobs ever held up to two years prior to diagnosis where exposure to electromagnetic fields above typical residential levels may have occurred

\begin{tabular}{|c|c|c|c|c|c|c|c|c|c|c|c|c|}
\hline \multirow[b]{2}{*}{ Exposed job ever held* } & \multicolumn{4}{|c|}{ Acute leukaemia } & \multicolumn{4}{|l|}{ AML } & \multicolumn{4}{|l|}{ ALL } \\
\hline & Case & Control & OR & $95 \% \mathrm{Cl}$ & Case & Control & OR & $95 \% \mathrm{Cl}$ & Case & Control & OR & $95 \% \mathrm{Cl}$ \\
\hline Never held any exposed job & 388 & 744 & 1 & - & 336 & 644 & 1 & - & 46 & 90 & 1 & - \\
\hline Computer systems and data processing managers & 5 & 2 & 3.95 & $(0.76$ to 20.5$)$ & 4 & 1 & 6.90 & $(0.77$ to 62.1$)$ & 1 & 1 & 1.14 & (0.06 to 20.2$)$ \\
\hline Software engineers & 1 & 1 & 2.13 & $(0.13$ to 34.6$)$ & 1 & 1 & 2.12 & $(0.13$ to 34.4$)$ & 0 & 0 & - & - \\
\hline Computer analysts/programmers & 7 & 14 & 1.17 & $(0.44$ to 3.09$)$ & 7 & 12 & 1.39 & (0.50 to 3.82$)$ & 0 & 2 & - & - \\
\hline Computer operators, data processing operators, office machine operators & 1 & 5 & 0.40 & $(0.05$ to 3.45$)$ & 1 & 4 & 0.47 & $(0.05$ to 4.33$)$ & 0 & 0 & - & - \\
\hline Computer engineers, installation and maintenance & 1 & 3 & 0.84 & $(0.07$ to 9.30$)$ & 1 & 3 & 0.83 & $(0.08$ to 9.26$)$ & 0 & 0 & - & - \\
\hline Electrical engineers & 1 & 7 & 0.22 & $(0.03$ to 1.86$)$ & 1 & 6 & 0.25 & $(0.03$ to 2.14$)$ & 0 & 1 & - & - \\
\hline Electronic engineers & 0 & 7 & - & - & 0 & 7 & - & - & 0 & 0 & - & - \\
\hline Electrical/electronic technicians & 1 & 7 & 0.19 & $(0.02$ to 1.70$)$ & 1 & 7 & 0.20 & $(0.02$ to 1.72$)$ & 0 & 0 & - & - \\
\hline Electricians, electrical maintenance fitters & 21 & 50 & 0.79 & $(0.46$ to 1.34$)$ & 17 & 40 & 0.79 & (0.44 to 1.43 ) & 4 & 9 & 0.82 & (0.24 to 2.79 ) \\
\hline Electrical engineers (not professional) & 2 & 3 & 1.96 & $(0.27$ to 14.0$)$ & 1 & 3 & 1.06 & $(0.10$ to 11.7$)$ & 1 & 0 & - & - \\
\hline Cable jointers, lines repairers & 0 & 5 & - & - & 0 & 5 & - & - & 0 & 0 & - & - \\
\hline Radio, TV, and video engineers & 5 & 5 & 1.60 & $(0.45$ to 5.69$)$ & 4 & 4 & 1.60 & $(0.38$ to 6.63$)$ & 1 & 1 & 1.69 & $(0.10$ to 27.5$)$ \\
\hline Other electrical/electronic trades not elsewhere classified & 7 & 10 & 1.73 & (0.62 to 4.83$)$ & 6 & 10 & 1.45 & $(0.50$ to 4.23$)$ & 1 & 0 & - & - \\
\hline Other secretaries, personal assistants, typists, word processor operators not elsewhere classified & 2 & 0 & - & - & 2 & 0 & - & - & 0 & 0 & - & - \\
\hline Telephone operators & 1 & 0 & - & - & 1 & 0 & - & - & 0 & 0 & - & - \\
\hline Radio and telegraph operators, other office communication system operators & 0 & 1 & - & - & 0 & 1 & - & - & 0 & 0 & - & - \\
\hline
\end{tabular}

Odds ratios, adjusted for deprivation, estimated using conditional logistic regression using never held an exposed job as the reference group. Risk estimates not calculated where no exposed cases or controls.

AML, acute myeloid leukaemia; ALL, acute lymphoblastic leukaemia.
$\star$ 
Table 5 Number of female ALL cases and total female controls, adjusted odds ratios, and $95 \%$ confidence intervals for jobs ever held up to two years prior to diagnosis where exposure to electromagnetic fields above typical residential levels may have occurred

\begin{tabular}{lrrll}
\hline Exposed job ever held* & Case & Control & OR & $95 \% \mathrm{Cl}$ \\
\hline Never held any exposed job & 25 & 522 & 1 & - \\
Computer analysts/programmers & 0 & 1 & - & - \\
$\begin{array}{l}\text { Computer operators, data processing operators, office } \\
\text { machine operators }\end{array}$ & 3 & 25 & 2.62 & (0.72 to 9.45) \\
Medical radiographers & 0 & 6 & - & - \\
Medical secretaries & 0 & 2 & - & - \\
Legal secretaries & 0 & 3 & - & - \\
Typists and word processor operators & 7 & 53 & 3.16 & (1.28 to 7.80) \\
$\begin{array}{l}\text { Other secretaries, personal assistants, typists, word } \\
\text { processor operators not elsewhere classified }\end{array}$ & 5 & 73 & 1.46 & $(0.53$ to 4.00) \\
Telephone operators & 1 & 9 & 3.19 & $(0.37$ to 27.2) \\
Radio and telegraph operators, other office communication & 0 & 2 & - & -
\end{tabular}

Odds ratios for an unmatched analysis estimated using logistic regression adjusted for age and deprivation using never exposed as reference. Risk estimates not calculated where no exposed cases.

*Exposed jobs ever held by women for a minimum of six months during the self reported work history; subjects may have held more than one exposed job.

(87\%) were diagnosed with acute myeloid leukaemia (AML), $92(12 \%)$ with acute lymphoblastic leukaemia (ALL), and 10 (1\%) had unspecified acute leukaemia (table 2). A slightly higher proportion of cases were men (56\%) and the mean age at diagnosis was 49.8 years. Based on self reported data, a higher proportion of cases than their matched controls were single, had left school by their 16th birthday, and had worked for 40 or more years, although such differences were not statistically significant. The census derived deprivation variable suggested a marginally significant difference $\left(\chi^{2}=12.95\right.$, $\mathrm{p}=0.07$ ) between the socioeconomic status of cases and controls, with cases tending to reside in more deprived areas than the controls. Subsequent analyses have been adjusted for deprivation.

Across all self reported jobs held for a minimum of six months, 120 cases $(16 \%)$ and $244(16 \%)$ controls were employed in occupations where exposure to electromagnetic fields at levels higher than typical residential exposure probably would have occurred (table 3 ). No associations with acute leukaemia were observed for probable electromagnetic field exposure ever, before, or at two years prior to diagnosis. When considering duration of exposure relative to those who were never exposed, odds ratios were not significantly different from one for less than 10 years, 10 to 19 years, or 20 or more years of electromagnetic field exposure (data not shown). Further, in all analyses, stratification by sex gave odds ratios close to one. Such null effects were dominated by the lack of associations observed for AML, the more prevalent lineage.

ALL, as opposed to AML, appeared to be associated with probable electromagnetic field exposure $(\mathrm{OR}=1.70,95 \% \mathrm{CI}$ 0.86 to 3.35$)$, because of an excess observed among women $(\mathrm{OR}=3.48,95 \%$ CI 1.18 to 10.2$)$, present for both current and past exposure. Investigation of the increased risk of ALL among women previously exposed to electromagnetic fields gave increased odds ratios with wide confidence intervals, relative to never exposed, for 20 or more years (four cases, $\mathrm{OR}=6.84,95 \%$ CI 0.98 to 47.9 ), 10 to 19 years (two cases, $\mathrm{OR}=1.22,95 \% \mathrm{CI} 0.17$ to 7.25 ), and less than 10 years (four cases, $\mathrm{OR}=11.16,95 \% \mathrm{CI} 0.95$ to 131 ) since exposure stopped. Risks of ALL were increased among females in all categories of exposure duration $(<10$ years, nine cases, $\mathrm{OR}=2.50,95 \%$ CI 0.70 to $8.90 ; 10-19$ years, three cases, $\mathrm{OR}=9.44,95 \%$ CI 0.64 to $138 ; 20+$ years, two cases, $\mathrm{OR}=5.73,95 \%$ CI 0.37 to 88.6). The increased risks for ALL among women still arose when compared to all female controls in an unmatched analysis (data not shown).
Data were examined by occupation among men for all diagnostic groups (table 4) and among women for ALL (table 5) relative to those persons never exposed. Odds ratios were not estimated where no cases or controls ever held a particular job. Among men, although increased, as well as decreased, risk estimates were observed across the various exposed occupations, all confidence intervals overlapped. Risks were increased for the four job categories ever held by a female ALL case, with only the risk among typists and word processor operators reaching statistical significance $(\mathrm{OR}=3.16,95 \%$ CI 1.28 to $7.80)$.

\section{DISCUSSION}

The study finds no evidence of an association between acute leukaemia and occupational exposure to electromagnetic fields in any time window relative to diagnosis. The data do not support a relation between AML and electromagnetic field exposure among either men or women. However, women, but not men, exposed at work show an increased risk of ALL. This association appears consistent for all durations of exposure, time periods since exposure ceased, and exposed occupations ever held.

"Electrical workers", a grouping of occupations first described by Milham ${ }^{2}$ as exposed to magnetic or electric fields, have been associated with leukaemia in all $^{2} 721-232526283031$ but a few published studies. ${ }^{24}{ }^{27} 29$ Although our definition of work related electromagnetic field exposure varied from Milham's definition to incorporate more recently exposed occupations for both men and women, the lack of an association with acute leukaemia remained when our data was restricted to "electrical workers" ( $\mathrm{OR}=0.73,95 \%$ CI 0.47 to 1.13 , based on 31 exposed cases and 81 exposed controls). Moreover, in such studies of "electrical workers" and other previously published data, ${ }^{2} 791112161921-2931$ 44-60 leukaemia or its subtypes have been inconsistently associated with specific occupations or industries where exposure to electromagnetic fields was likely.

Previously, dose-response relations have been tested using job specific magnetic, electric, or pulsed electromagnetic field metrics accumulated across a work history. ${ }^{4-6} 8-111^{14} 1^{18-20}$ Where no exposure estimates are available, duration of exposure provides an alternative to the cumulative dose variable. Like the studies of leukaemia testing for trends with cumulative dose, there is little evidence of a linear increase in risk here, or elsewhere, ${ }^{9}$ with the number of years employed in an occupation where exposure to electromagnetic fields might occur. But, whether the dose variable is generated via a matrix of exposure levels within specific tasks or by probabilities of 
exposure for occupational codes, there is the potential for non-differential misclassification of exposure leading to the dilution of any dose-response effect.

Although lifetime employment histories collected in a casecontrol study permit the assessment of time windows with respect to the time of the case's diagnosis, no increased risk of acute leukaemia was observed in our data for any period prior to diagnosis since exposure ceased. Similarly, in other published analyses, restricting the cumulative dose of magnetic or electric fields to $2-12$ or $5-25$ years, ${ }^{510}$ or $0-5$, $0-20$, or 20 years or more ${ }^{8}$ prior to diagnosis gave little evidence of an association with leukaemia. In one study, an increasing risk of leukaemia with increasing exposure levels of the magnetic field strength's mean, median, standard deviation, or time above $0.2 \mu \mathrm{T}$ in the job held longest within the 10 years prior to diagnosis was found, but these rising trends were not observed for AML. ${ }^{3}$ So, to date, constructing time windows relative to diagnosis has largely failed to determine a critical exposure period.

While most of the studies report risks for men, women are seldom studied. ${ }^{173052535561}$ Frequencies of female leukaemia cases in the exposed jobs as identified by Milham ${ }^{2}$ are typically small, $^{30525561}$ but even where larger numbers are available, with employment in the telephone industry ${ }^{53}$ or with mean magnetic field exposure in the occupation recorded on the 1970 Swedish census, ${ }^{17}$ associations are, at best, weak. As such, subsequent analyses by subtypes of leukaemia, especially ALL, among women have rarely been attempted; one study found little evidence of an association between ALL and mean magnetic field exposure in the job held at the time of the 1970 Swedish census, ${ }^{17}$ while two others observed no cases of ALL among female electrical workers. ${ }^{3055}$ Hence there are little available data to compare with our observed increased risk of ALL among women probably exposed to electromagnetic fields at work.

Within the data presented here, the construction of the job exposure matrix from the description of occupational codes could have weakened the observed risks. Occupational codes, and indeed the jobs of similar skills and activities described by a SOC code itself, are possibly heterogeneous for strength, frequency, and/or other characteristics of electromagnetic field exposure. Persons employed in occupations considered probably exposed to electromagnetic fields are not necessarily exposed to stronger magnetic or electric fields than vocations deemed unexposed; for instance, electricians often work with "dead" equipment. ${ }^{62}$ Further, some SOC occupational codes defined as unexposed include jobs where high exposure to electromagnetic fields probably occurs. Most notably, the matrix does not encompass electric welders, seamstresses, railway workers, and electric power utility workers. Exclusion was decided on an ambiguous occupational code or uncertain exposure. Among the four examples, (i) electric, in addition to gas, welders describe the occupational code "welding trades"; (ii) sewing machinists are grouped with menders, darners, and embroiders, work not requiring a sewing machine; (iii) railway workers in the UK are not necessarily exposed as many trains run on diesel rather than electricity; and (iv) electric utility workers, other than those employed in occupations described in table 1 , are classed with other energy plant operatives and attendants. With the inclusion of these four occupational groups into our probable exposure definition, the risk remained non-significant (men: OR $=0.89,95 \%$ CI 0.64 to 1.23, based on 65 exposed cases and 141 exposed controls; women: OR $=1.22,95 \%$ CI 0.92 to 1.63 , based on 107 exposed cases and 182 exposed controls). Besides potential nondifferential misclassification of exposure status arising from the use of this job exposure matrix, the true risk may be further reduced since exposure in some non-occupational environments may be as high as encountered in many occupational settings, although the use here of controls matched to cases on area of residence may partially control for domestic exposure.
Over time, the likelihood of electromagnetic field exposure for many probably exposed occupations in the exposure matrix is not likely to have changed, while other professions, such as computer systems and data processing managers, and software engineers, are recently defined occupations. The exceptions are secretaries, typists, and personal assistants who would not be exposed to higher levels of electromagnetic fields prior to the introduction of word processors, photocopiers, visual display units, and other electrical office equipment. As largely female vocations, secretarial occupations contribute to the observed increased risk of ALL among women probably exposed to electromagnetic fields, yet the increased odds ratio remains irrespective of time prior to diagnosis since exposure ceased.

Participation of subjects, retrospective collection of self reported data, and use of information supplied by proxies may influence the risk estimates. Controls had a higher refusal rate than cases and non-participating subjects are more likely to live in areas of lesser affluence than interviewees. The majority of occupations probably exposed to electromagnetic fields belong to the socioeconomic group of skilled manual workers or below, ${ }^{63}$ and so persons employed in exposed jobs may have resided in more deprived areas. Hence a false positive association between ALL and probable exposure to electromagnetic fields among women is possible but adjustment for deprivation hardly alters the risk estimate (unadjusted $\mathrm{OR}=3.62,95 \%$ CI 1.25 to 10.5$)$. Alteration of the true risk could be a consequence of the self reported retrospective collection of data, particularly for a well publicised hypothesis like leukaemia and electromagnetic fields. Although it cannot be certain, the collection of occupations rather than self reported exposure to electromagnetic fields should lessen potential over-reporting by subjects. Proxy information too may be unreliable. Removal of the data collected from surrogates for three female ALL cases does not greatly change the odds ratios for probable electromagnetic field exposure $(\mathrm{OR}=4.48,95 \%$ CI 1.40 to 14.4 , based on 13 exposed cases and 10 exposed controls), number of years exposed, and number of years since exposure stopped (data not shown).

Our raised risk of ALL among women is probably not caused by occupational exposure to electromagnetic fields given that the odds ratios are increased during periods when exposure above background levels is improbable; moreover, men, who are employed in occupations with greater electromagnetic field exposure, were not at increased risk of ALL. The increased risk estimate is not confounded by the total number of years worked $(\mathrm{OR}=5.25$, 95\% CI 1.41 to 19.6$)$ and, since the majority of exposed subjects were employed in secretarial or computer work, it is not likely to be confounded by an occupational exposure. It is possible that a lifestyle factor may affect the observed risk. Adjustment for smoking status two years prior to diagnosis did not reduce the odds ratio (OR $=4.63,95 \%$ CI 1.45 to 14.8 ). Regrettably, this study did not collect information on other lifestyle factors such as alcohol consumption ${ }^{64-70}$ and variations in diet. ${ }^{71} 72$

This large population based case-control study found little evidence to support an association between occupational exposure to electromagnetic fields and acute leukaemia. Although an excess of acute lymphoblastic leukaemia among women was observed, it is unlikely that occupational exposure to electromagnetic fields was responsible given that increased risks remained during periods when exposure above background levels was improbable. The lack of an association observed here for acute leukaemia is largely consistent with epidemiological studies using quantitative estimates of personal electromagnetic field exposure, and the in vivo and in vitro laboratory investigations of leukaemogenesis, or more broadly carcinogenesis, which have failed to establish a plausible biological mechanism. ${ }^{73}$ However, occupational codes remain a surrogate for exposure and as such, in the absence of a biologically relevant parameter, the most comprehensive 


\section{Main messages}

- A new definition of work related electromagnetic field exposure based on the 1990 UK standard occupational classification scheme is applied to self reported employment histories.

- This large population based case-control study suggests that there is no association between acute leukaemia and probable occupational exposure to electromagnetic fields.

- Neither men nor women are at increased risk of acute myeloid leukaemia following probable occupational exposure to electromagnetic fields.

- Women, but not men, have an excess of acute lymphoblastic leukaemia irrespective of the time period employed in an occupation considered exposed to electromagnetic fields.

\section{Policy implications}

- As occupational codes are a surrogate for exposure, the most comprehensive future studies should utilise personal dosimetry to characterise the strengths, frequencies, and other electromagnetic field metrics within specific work tasks.

future epidemiological studies should utilise personal dosimetry to characterise the strengths, frequencies, and other electromagnetic field metrics within specific work tasks.

\section{ACKNOWLEDGEMENTS}

We thank all consultants, hospital staff, general practitioners, and interviewees who participated in the study, and the study staff. B Pannett and $\mathrm{K}$ Baker are acknowledged for their work in developing the job exposure matrix. GJ Dovey, GR Law, F Mensah, and AG Smith are thanked for their comments on the manuscript.

\section{Authors' affiliations}

E V Willett, N T Fear, R A Cartwright, E Roman, Leukaemia Research Fund Epidemiology and Genetics Unit, Margaret Smith Building, University of Leeds, Leeds LS2 9JT, UK

P A McKinney, Paediatric Epidemiology Group, Margaret Smith Building, 30 Hyde Terrace, Leeds LS2 9LN, UK

\section{REFERENCES}

Wertheimer $\mathbf{N}$, Leeper $N$. Electrical wiring configurations and childhood cancer. Am J Epidemiol 1979;109:273-84.

2 Milham S Jr. Mortality from leukemia in workers exposed to electrical and magnetic fields. N Engl J Med 1982;307:249.

3 Floderus B, Persson T, Stenlund C, et al. Occupational exposure to electromagnetic fields in relation to leukemia and brain tumors: case-control study in Sweden. Cancer Causes Control 1993;4:465-76.

4 Matanoski GM, Elliott EA, Breysse PN, et al. Leukemia in telephone linemen. Am J Epidemiol 1993;137:609-19.

5 Sahl JD, Kelsh MA, Greenland S. Cohort and nested case-control studies of hematopoietic cancers and brain cancer among electric utility workers. Epidemiology 1993;4:104-14.

6 Armstrong B, Thériault G, Guénel P, et al. Association between exposure to pulsed electromagnetic fields and cancer in electric utility workers in Quebec, Canada, and France. Am J Epidemiol $1994 \cdot 140 \cdot 805-20$

7 London SJ, Bowman JD, Sobel E, et al. Exposure to magnetic fields among electrical workers in relation to leukemia risk in Los Angeles County. Am J Ind Med 1994;26:47-60.

8 Thériault G Goldberg M, Miller $A B$, et al. Cancer risks associated with occupational exposure to magnetic fields among electric utility workers in Ontario and Quebec, Canada, and France: 1970-1989. Am J Epidemiol 1994; 139:550-72.

9 Tynes T, Reitan JB, Andersen A. Incidence of cancer among workers in Norwegian hydroelectric power companies. Scand J Work Environ Health 1994:20:339-44.

10 Tynes T, Jynge H, Vistnes Al. Leukemia and brain tumors in Norwegian railway workers, a nested case-control study. Am J Epidemiol 1994; 139:645-53

11 Savitz DA, Loomis D. Magnetic field exposure in relation to leukemia and brain cancer mortality among electric utility workers. Am J Epidemiol $1995 ; 141: 123-34$
12 Baris D, Armstrong BG, Deadman J, et al. A mortality study of electrical utility workers in Québec. Occup Environ Med 1996;53:25-31.

13 Guénel P, Nicolau J, Imberon E, et al. Exposure to $50-\mathrm{Hz}$ electric field and incidence of leukemia, brain tumors, and other cancers among French electric utility workers. Am J Epidemiol 1996;144: 1 107-2 1 .

14 Miller AB, To T, Agnew DA, et al. Leukemia following occupational exposure to $60-\mathrm{Hz}$ electric and magnetic fields among Ontario electric utility workers. Am J Epidemiol 1996;144:150-60

15 Kheifets LI, London SJ, Peters JM. Leukemia risk and occupational electric field exposure in Los Angeles County, Calfornia. Am J Epidemiol 1997:146:87-90

16 Johansen C, Olsen JH. Risk of cancer among Danish utility workers-a nationwide cohort study. Am J Epidemiol 1998;147:548-55

17 Floderus B, Stenlund C, Persson T. Occupational magnetic field exposure and site-specific cancer incidence: a Swedish cohort study. Cancer Causes Control 1999:10:323-32.

18 Kheifets LI, Gilbert ES, Sussman SS, et al. Comparative analyses of the studies of magnetic fields and cancer in electric utility workers: studies from France, Canada, and the United States. Occup Environ Med 1999;56:567-74

19 Harrington JM, Nichols L, Sorahan T, et al. Leukaemia mortality in relation to magnetic field exposure: findings from a study of United Kingdom electricity generation and transmission workers, 1973-97. Occup Environ Med 2001;58:307-14

20 Minder CE, Pfluger DH. Leukemia, brain tumors, and exposure to extremely low frequency electromagnetic fields in Swiss railway employees. Am J Epidemiol 2001;153:825-35.

21 Wright WE, Peters JM, Mack TM. Leukaemia in workers exposed to electrical and magnetic fields. Lancet 1982;2:1160-1.

22 McDowall ME. Leukemia mortality in electrical workers in England and Wales. Lancet 1983;1:246.

23 Coleman $M$, Bell J, Skeet R. Leukaemia incidence in electrical workers. Lancet 1983;1:982-3.

24 Calle EE, Savitz DA. Leukemia in occupational groups with presumed exposure to electrical and magnetic fields. N Engl J Med 1985;313:1476-7

25 Pearce NE, Sheppard RA, Howard JK, et al. Leukaemia in electrical workers in New Zealand. Lancet 1985;i:811-12.

26 Pearce N, Reif J, Fraser J. Case-control studies of cancer in New Zealand electrical workers. Int J Epidemiol 1989:18:55-9.

27 Loomis DP, Savitz DA. Mortality from brain cancer and leukaemia among electrical workers. Br J Ind Med 1990;47:633-8.

28 Robinson CF, Lalich NR, Burnett CA, et al. Electromagnetic field exposure and leukemia mortality in the United States. J Occup Med 1991;33:160-2.

29 Tynes T, Andersen A, Langmark F. Incidence of cancer in Norwegian workers potentially exposed to electromagnetic fields. Am J Epidemiol 1992;136:81-8

30 Fear NT, Roman E, Carpenter LM, et al. Cancer in electrical workers: an analysis of cancer registrations in England, 1981-87. Br J Cancer 1996;73:935-9.

31 Bethwaite P, Cook A, Kennedy J, et al. Acute leukemia in electrical workers: a New Zealand case-control study. Cancer Causes Control $2001 ; 12: 683-9$

32 Kane EV, Roman E, Cartwright R, et al. Tobacco and the risk of acute leukaemia in adults. Br J Cancer 1999:81:1228-33.

33 Employment Department Group, Office of Population Censuses and Surveys. Standard occupational classification. London: HMSO, 1990.

34 Central Statistical Office. Standard industrial classification. London: HMSO, 1980

35 UK Childhood Cancer Study Investigators. The United Kingdom Childhood Cancer Study: objectives, materials and methods. Br J Cancer 2000;82:1073-102.

36 McCormick A, Fleming D, Charlton J. Morbidity statistics from general practice. Fourth national study 1991-1992. London: HMSO, 1995.

37 Rinsky RA, Smith AB, Hornung R, et al. Benzene and leukemia. An epidemiologic risk assessment. N Engl J Med 1987;316:1044-50.

38 Aksoy M. Benzene as a leukemogenic and carcinogenic agent. Am J Ind Med 1985;8:9-20.

39 Curtis RE, Hankey BF, Myers MH, et al. Risk of leukemia associated with the first course of cancer treatment: an analysis of the surveillance, epidemiology, and end results program experience. J Natl Cancer Inst 1984;72:531-44.

40 Smith PG, Doll R. Mortality among patients with ankylosing spondilitis after a single course with x-rays. BM 1982;284:449-60.

41 Townsend P, Phillimore P, Beattie A. Health and deprivation: inequality and the North. London: Croom Helm, 1988

42 Breslow NE, Day NE. Classical methods of analysis of matched data. In: Davis W, ed. The analysis of case-control studies. Lyon: International Agency for Research on Cancer, 1980:162-89.

43 Stata Corporation. Intercooled Stata 7.0 for Windows 98/95/NT. Texas, 2001

44 Flodin U, Fredriksson $M$, Persson B, et al. Background radiation, electrical work, and some other exposures associated with acute myeloid leukemia in a case-referent study. Arch Environ Health 1986;41:77-84.

45 Cartwright RA, Darwin C, McKinney PA, et al. Acute myeloid leukemia in adults: a case-control study in Yorkshire. Leukemia 1988;2:687-90.

46 Linet MS, Malker HSR, Mclaughlin JK, et al. Leukemias and occupation in Sweden: a registry-based analysis. Am J Ind Med 1988;14:319-30.

7 Gubéran E, Usel M, Raymond L, et al. Disability, mortality, and incidence of cancer among geneva painters and electricians: a historical prospective study. Br J Ind Med 1989;46:16-23. 
48 Gallagher RP, McBride ML, Band PR, et al. Occupational electromagnetic field exposure, solvent exposure and leukemia. J Occup Med 1990;32:64-5.

49 Garland FC, Shaw E, Gorham ED, et al. Incidence of leukemia in occupations with potential electromagnetic field exposure in United States Navy personnel. Am J Epidemiol 1990;132:293-303.

50 Loomis DP, Savitz DA. Occupation and leukemia mortality among men in 16 states: 1985-1987. Am J Ind Med 1991;19:509-21.

51 Törnqvist S, Knave B, Ahlbom A, et al. Incidence of leukaemia and brain tumours in some "electrical occupations". Br J Ind Med 1991:48:597-603

52 Guénel P, Raskmark P, Andersen JB, et al. Incidence of cancer in persons with occupational exposure to electromagnetic fields in Denmark. $\mathrm{Br}$ J Ind Med 1993;50:758-64.

53 Dosemeci M. Blair A. Occupational cancer mortality among women employed in the telephone industry. J Occup Med 1994;36:1204-9.

54 Floderus B, Törnqvist S, Stenlund C. Incidence of selected cancers in Swedish railway workers, 1961-79. Cancer Causes Control 1994;5: 189-94.

55 Linet MS, McLaughlin JK, Malker HSR, et al. Occupation and hematopoietic and lymphoproliferative malignancies among women: linked registry study. J Occup Med 1994;36:1187-98.

56 Alfredsson L, Hammar N, Karlehagen S. Cancer incidence among male railway engine-drivers and conductors in Sweden, 1976-90. Cancer Causes Control 1996:7:377-81.

57 Danielsen TE, Langård S, Andersen A. Incidence of cancer among Norwegian boiler welders. Occup Environ Med 1996;53:231-4 58 Kelsh MA, Sahl JD. Mortality among a cohort of electric utility workers, 1960-1991. Am J Ind Med 1997;31:534-44.

59 Robinson CF, Petersen M, Palu S. Mortality patterns among electrical workers employed in the U.S. construction industry, 1982-1987. Am J Ind Med 1999;36:630-7

60 Van Wijngaarden E, Savitz DA, Kelckner RC, et al. Mortality patterns by occupation in a cohort of electric utility workers. Am J Ind Med 2001;40:667-73.
61 Miligi L, Costantini AS, Crosignani P, et al. Occupational, environmental and life-style factors associated with the risk of hematolymphopoietic and life-style factors associated with the risk of hematoly
malignancies in women. Am J Ind Med 1999;36:60-9.

62 Savitz DA, Calle EE. Leukemia and occupational exposure to electromagnetic fields: review of epidemiologic surveys. J Occup Med 1987;29:47-51.

63 Office of Population Censuses and Surveys. Social classifications and methodology. Standard occupational classification, Vol. 3. London: HMSO, 1991:1-56.

64 Williams RR, Horm JW. Association of cancer sites with tobacco and alcohol consumption and socioeconomic status of patients: interview study from the Third National Cancer Survey. J Natl Cancer Inst 1977;58:525-47.

65 Jensen OM. Cancer morbidity and causes of death among Danish brewery workers. Int J Cancer 1979;23:454-63.

66 Blackwelder WC, Yano K, Rhoads GG, et al. Alcohol and mortality: the Honolulu Heart Study. Am J Med 1980;68: 164-9.

67 Hinds MW, Kolonel LN, Lee J, et al. Associations between cancer incidence and alcohol/cigarette consumption among five ethnic groups in Hawaii. Br J Cancer 1980;41:929-40.

68 Schmidt W, Popham RE. The role of drinking and smoking in mortality from cancer and other causes in male alcoholics. Cancer 1981;47:1031-41.

69 Carstensen JM, Bygren LO, Hatschek T. Cancer incidence among Swedish brewery workers. Int J Cancer 1990;45:393-6.

70 Brown LM, Gibson R, Burmeister LF, et al. Alcohol consumption and risk of leukemia, non-Hodgkin's lymphoma, and multiple myeloma. Leukemia Res 1992; 16:979-84

71 Hursting SD, Margolin BH, Switzer BR. Diet and human leukemia: an analysis of international data. Prev Med 1990;19:242-53.

72 Kwiatkowski A. Dietary and other environmental risk factors in acute leukaemias: a case-control study of 119 patients. Eur J Cancer Prev 1993;2:139-46.

73 National Radiological Protection Board. ELF electromagnetic fields and the risk of cancer. Report of an Advisory Group on Non-ionising Radiation. In: Doll R, ed. Documents of the NRPB, Vol. 12. Didcot: National Radiological Protection Board, 2001:1-179.

\section{$\mathrm{ECHO}$}

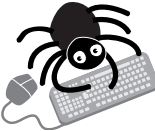

Please visit the Occupational and

Environmental Medicine website [www. occenvmed.com for link to this full article.

\section{Car communications systems tailored for elderly drivers have wider spinoffs}

D

esigning vehicle information and assistance systems along ergonomic principles that suit elderly drivers will increase safety for drivers of all ages, claims a review. Importantly, too, it will help to prevent elderly drivers from becoming marginalised. The systems fall into two camps. Information systems give guidance, traffic information, and warnings. Assistance systems can automatically correct for indecision or slow reactions to immediate hazards.

Ergonomics research has an important input into the design and evaluation phases of these systems and the iterative process that links the two. Focusing on the ergonomicsacceptability, ease of use, and safety-specifically for older drivers ensures that the systems compensate for deficiencies or waning abilities in perception, reading the road, and movement. But it has payoffs for younger drivers.

Research in road laboratories or out on the road shows how to present screen instructions to reduce the length of glance by elderly drivers to that by younger drivers. Readily legible screen guidance systems and displayed sequences of the road, junction by junction, are easier to interpret by young and older drivers alike than an electronic map with a highlighted route, which older drivers find especially tricky. Analysing drivers' mental workload to tailor the systems to get the best driving performance is complex, but there are some tools to help with this. Even small features like volume and contrast controls and route finding avoiding motorways make a big difference to elderly drivers.

Ultimately, if ergonomics researchers and car designers and builders get it right these systems might benefit all road users, not just elderly drivers most at risk of accidents.

A Injury Prevention 2002;8(Suppl IV):iv26-iv29. 